\title{
Crowd Sourcing Disaster Management: The Complex Nature of Twitter Usage in Indonesia
}

Kathleen M. Carley ${ }^{1}$, Momin Malik, Peter M. Landwehr, Jürgen Pfeffer, Mike Kowalchuk \{kathleen.carley, momin.malik, plandweh, jpfeffer, kf3cr\}@cs.cmu.edu

Carnegie Mellon University

School of Computer Science

Institute for Software Research

5000 Forbes Avenue,

Pittsburgh, PA 15213

${ }^{1}$ Corresponding Author: Prof. Kathleen M. Carley (kathleen.carley@cs.cmu.edu), Institute for Software Research, Carnegie Mellon University, Pittsburgh, PA 15213 USA. 


\section{Crowd Sourcing Disaster Management: The Complex Nature of Twitter Usage in Padang Indonesia}

\section{1 - Introduction}

Government officials, first responders and the general public are increasingly looking to social media as a critical communication and monitoring tool for disaster management. Due to widespread press coverage and ease of data collection, Twitter in particular is viewed as a critical communication media for disaster management. Key advantages include crowd-sourcing, speed, and the ability to access from mobile devices. Key potential disadvantages include bias in user base; inaccurate, false, and out-of-date information; and reduction in access due to cell-tower and electricity outages. The discussion of the strengths and weaknesses of Twitter for disaster management is typically based on anecdotes and isolated case studies of usage during a disaster or in its immediate aftermath. Such studies, however, do not address the value of Twitter data for early warning and planning vis-à-vis disasters such as Tsunamis. For early warning and planning the key is not how do people use Twitter once the disaster has occurred; but, how can the normal usage of Twitter be leveraged to support early warning and planning? The relevant questions include: How can we leverage the information garnered from everyday normal uses of Twitter to improve disaster planning and inform an effective early warning system? How should Twitter data be collected to support early warning and planning for disasters? How can information extracted from the normal usage of Twitter be leveraged to support early warning and planning? In this paper, we address such questions for Padang Indonesia.

This research is part of a larger effort that seeks to provide a socio-technical system that supports early warning and planning for Tsunamis. A key feature of this socio-technical system is the use of Twitter to provide early warning that a Tsunami is coming (Landwehr, et al, this issue), to provide up-to-date information and guidance for movement to shelters (Santos et al, this issue), and to support planning for Tsunami's (Landwehr, et al, this issue). Effective planning and alerts require knowing where the local population is, who is on-line, what languages they can communicate in, whom they communicate with, and who the local opinion leaders are. Such information cannot be adequately gained from a census, as a census only provides information on average and is typically out-of-date. In theory, social media has the potential to improve the accuracy and timeliness of this "census" information and so improve planning and alerts.

To determine whether or not such "census" information is attainable from Twitter, its accuracy, and what collection strategy improves the information quality, a baseline analysis of the use of Twitter in Indonesia in general, and Padang in particular was conducted. This baseline assessment was then used to identify the best data collection strategy, which was then implemented in the Tsunami Warning and Response Social Media System (TWRsms) (Landwehr, et al, this issue), and to identify the limits of and biases in Twitter data that effect its utility as part of an early warning system. The results from this study influenced the design of the overall system - see Santos et al, this issue and Ai et al, this issue. This study provided an understanding of which areas in the target region (Padang) most used Twitter, identified the best strategy to collect population data, and provided baseline data for the fraction of the population active in each region by time of day and day of week.

In general, government agencies and first responders do not understand how social media can be used for disaster planning and early warning. Our discussions with such planners suggests that they assume that access to the Twitter decahose (10\% of all tweets) is better than self-collecting data ( $1 \%$ of all tweets), that one can create a list of disaster terms and use that to identify relevant tweets, and that those on Twitter may reflect the actual population. Further, it is generally thought 
that since social media is a "fast way to communicate" that warnings sent by media like Twitter will be picked up and communicated broadly. This assumes that local Twitter opinion leaders will be listened to by the community at large. Herein, we examine normal everyday Twitter usage in Padang Indonesia, in order to determine whether such assumptions are warranted. This is critical for developing a Twitter enabled disaster planning and early warning system.

We do not address how Twitter is used during a disaster for disaster related communication that is not our objective; rather, we examine the biases in the normal use of Twitter and the way data is collected that affect its utility as a tool for providing the information needed for planning and effective alerts. While our data provides some guidance for coordination during disasters, that is not our focus. Thus, this paper is informative about what data to collect and how to collect it to support planning activity. It is about the strengths and limitations of Indonesian Tweets for planning and warning, and not about how Indonesian's use Twitter during a disaster. Without understanding the biases, imposed by the data collection strategy, the technology, or the culture that is producing the tweets, one cannot use the data sensibly for planning or warning.

Why should disaster management studies be concerned with social media in general and Twitter in particular? Social media is used at all phases of disaster management (Carley, 2014; Landwehr \& Carley, forthcoming), early warning (Landwehr et al, this issue), communication and organization during disasters and in their aftermath (Hossman et al., 2011), and identification of critical needs in the early response (Muralidharan et al., 2011). Social media in general, and Twitter specifically, are often hailed as "the next generation" in crisis response tools (Terpstra et al., 2012; Palen et al. 2008, Palen et al 2009, Sutton et al 2008). Twitter has risen to particular prominence because its API has made searching for and storing disaster related content relatively trivial (Vieweg et al, 2010; Palen, 2008). Attention to Twitter data during a disaster increases situational awareness and supports resilience (Tobias, 2011; Palen et al. 2010). However, social media data can be difficult to use in a disaster context. For example, in Twitter, the tweets may be inaccurate (Thomson et al, 2012), false (Tinker \& Vaughan, 2010), outdated (Acar \& Muraki, 2011), filled with irrelevant information (Hughes \& Palen, 2009; Acar \& Muraki, 2011), or contain harmful rumors (Castillo et al, 2011) thus increasing distrust and chaos. Despite the widespread usage of Twitter during disasters, little is known about whether non-disaster tweets can be used to plan for a response or warning strategy; other than the fact that, tweets from government and official responders are more retweeted and so better meet the public's need to know than those by random individuals (Thomson et al, 2012). This paper fills this gap.

Why is Indonesia a good venue for assessing the utility of Twitter data for disaster management? It is one of the top five nations invested in social media in general, and Twitter in particular. It is impacted frequently by often devastating natural disasters - tsunamis, volcanic eruptions, earthquakes, and floods (Diley, 2005; Peduzzi et al., 2009); (Center for Excellence in Disaster Management \& Humanitarian Assistance, 2011). Indonesia is undergoing rapid sociocultural transformations with a growing political and scientific community concerned with social media and disaster management (Philpott, 2000; Couldray \& Curran, 2003), against a backdrop of social-media usage by terrorists and human-traffickers (Eickelman \& Anderson, 2003).

We examine the issues in using Twitter to support disaster planning and early warning, with special attention to its use in Padang Indonesia for tsunamis. First we identify what issues need to be addressed to use Twitter to support planning and early warning. Second, we consider the sociotechnical context to identify the affordances and constraints in using Twitter. Given the context of Twitter use in disasters, and the special problems arising for tsunamis, we review the nature of Twitter, its use in Indonesia, the socio-cultural context and the relevant disaster context. Third, we 
describe alternative collection scenarios and assess the strengths and weaknesses of these for providing data to support planning and early warnings. Fourth, we analyze collected data to characterize normal Twitter usage in Padang Indonesia. Inherent data biases that relate to coverage, spatio-temporal patterns, and identification of local opinion leaders are identified. This assessment informs the planning and alert system described in this issue.

\section{2 - Disaster Context}

While knowledge management is not a new concept for disaster responders, each disaster is generally treated as an entirely new problem for which responders build new knowledge structures on the fly and decision makers take action on the basis of this hastily constructed data (Yates \& Paquette, 2011). Despite good intentions, poor decisions often result from inconsistent, inaccurate or incomprehensive information. A knowledge management system for disasters needs a number of capabilities including (Zhang et al., 2002): the ability to evaluate the severity of the disaster, by population and location, and the ability to generate timely and specific warnings, that can reach the populations at risk. To do this requires knowing where people are likely to be and how to reach them. Normal Twitter usage provides guidance here, as it captures an up-to-date image of where people are and who is reaching whom. To determine the utility of this information we need to assess the coverage - i.e. How biased is this sample population, and then use this information to provide guidance on spatio-temporal patterns and opinion leaders.

Coverage: How "good" is the Twitter coverage of the local population? The danger of using internet-based technologies that are not held representatively is that decisions based on these may reinforce existing inequalities or create new ones (Thomas, 1995), lead to the propagation of rumors, and provide an illusion of accurate response (Quarantelli, 1997). As noted by Mackay (1995, p. 47) "The use and meaning of information and communication technologies in the home [and the workplace] ... can only be understood within the class, gendered, geographical and generational context of its consumption." If the volume of usage is too low, then it may not be worth investing scarce resources into Twitter support for disaster management. The composition of Twitter users will suggest which sub-populations are potentially reachable by Twitter alerts, and which will need to be reached by other means. The languages of the tweets will provide guidance on: which language to send alerts in, which regions have special linguistic needs, and whether those linguistic patterns of need vary by time of day.

Spatio-Temporal Patterns: How "good" is the Twitter coverage of where the population is when? In many disasters power either goes out or becomes intermittent, thus mitigating the use of computer-based technologies (Quarantelli, 1997). However, early warning and planning are more impacted by the pernicious problem that the technology may not be being used 24/7. Pattern of life activity, which varies by region, will be a determinant of the utility of a media for gathering data, making projections, and alerting the population. Geo-information provides the opportunity to aid in evacuation and response; however, the value of such information depends on its accurateness and up-to-date-ness (van Oosterom, et al., 2006; Earle, et al., 2011). Social media can be used to map crises, see for example the United Nations crisis map (Meier, 2012). Tweets can contain overt geographic information in two ways - either the user can elect to share their latitude and longitude, or they can list a location - e.g., Padang. Further, location and language information can be used to improve spatial inference (Leetaru et al., 2013). Latitude and longitude data are used to support disaster management and response activities (Power et al., 2014). Nevertheless, relatively few tweets have any geo-information; thus, the critical question is: is there a sufficient geo-temporal signal to help inform planning and warning activities? 
Opinion Leaders: Can Twitter be used to identify the local opinion leaders, and so mobilize them to provide early warnings to the populace? Twitter can be used as a news source and so support information diffusion. Formal authoritative sources such as the Meteorological, Climatological and Geophysical Agency of Indonesia (Badan Meteorologi, Klimatologi, Dan Geofisika - BMKG) are using Twitter in this way. However, they may not be local opinion leader - those with a large following, who are highly central in the co-mentions network, and frequently send tweets that are retweeted. Twitter will be useful for early warning if it can be used to identify and mobilize opinion leaders.

\section{3 - Socio-Cultural-Technical Context}

Computers should be part of the disaster management team (Carver \& Turoff, 2007); hence, so should social media such as Twitter. This helps to ensure that people continue to do what they do well and are supported by social media, rather than driven by it. To be part of the team, Twitter must help address three key problems - communication, coordination, and the exercise of authority (Quarantelli, 1988). A key question is can Twitter data provide more accurate, timely, relevant and geographically situated information (Guha-Sapir \& Lechtat, 1986; van Oosterom, et al., 2006) than census data, and so support planning? To answer this question it is necessary to understand data biases and so know when the Twitter data is not informative. What are the data biases?

\section{1 - Twitter}

Twitter is a 'microblogging' service, where users sign up for free, choose a 'handle,' and get a profile accessible at Twitter.com/[handle]. Users can post messages ('tweets') of a maximum of 140 characters. By tagging other's user-handles with “@” symbols, their tweets appear on the profiles of others, thereby engaging in conversations. By adding a hash symbol ('\#') before a word, it is made into a Twitter searchable category. These hashtags serve multiple purposes, such as labels, summarizations, and topic indicators. By posting and searching for hashtags (e.g., \#worldcup), ${ }^{1}$ users can participate in larger conversations, and get to know users to whom they are not otherwise connected. Users can 'follow' other users, causing others' tweets to appear on a section of their profile. In a disaster context, users with more followers will be more effective at spreading early warnings. From its launch in 2006 to 2014 Twitter had grown to 284 million monthly active users, sending about 500 million Tweets are per day, of which about $80 \%$ are from mobile devices. Users include individuals, corporations, news agencies, government units, and bots ('robot' accounts run automatically with computer scripts). Governmental and corporate users typically have policies on how they use Twitter, what hashtags are allowed, and whether they can refer to or retweet other users. Some user accounts are 'verified;' i.e., Twitter has investigated and determined that they are not bots and belong to the public figure or corporation claiming them. Only a few accounts are verified and often have higher followership; e.g., high profile entertainment, news, corporate, and political accounts.

Twitter has an API (Application Programming Interface) to which developers and researchers can submit text-based queries in pre-specified formats to which Twitter will return text-only data (instead of including images, or rendering these data in a graphical interface). Developers may use

\footnotetext{
${ }^{1}$ Hashtags are not sensitive to capitalization, and cannot include spaces. This can create confusion, such as when Margaret Thatcher dies and many tweeters seeing the hashtag \#nowthatchersdead thought that the singer Cher had died. http://www.salon.com/2013/04/08/internet confused by nowthatchersdead hashtag on Twitter/ last accessed - Feb. 2015. Hashtags can be obscure, as they are often idiosyncratic abbreviations that are code for certain practices, e.g., \#tbt stands for "Throwback Thursday," where users post old pictures along with this hashtag in a public display of nostalgia. Finally, hashtags sent for one purpose are sometimes usurped for other purposes.
} 
this data to make applications on top of Twitter, such as TWRsms (Landwehr et al., this issue) and TweetTracker (Kumar et al., 2011; Kumar \& Morstatter, 2011), and researchers may use the data to study Twitter (Gaffney \& Puschmann 2013; Kumar, Morstatter \& Liu, 2015). The 'Streaming API' will return 50 tweets per second, or 3000 per minute with the maximum not to exceed 300 tweets for parameters selected such as all tweets of a given user, tweets with a certain hashtag, tweets sent by users who have the geo-code enabled and which fall within the latitudes and longitudes that define a box of geographic coordinates of interest to the observer, etc. However, when the number of potential matches to a query exceeds the rate limits, the sample may not be random which may distort results (Morstatter et al. 2013). The 'Sample API' gives a consistent $1 \%$ sample of all tweets, but with no ability to focus on a particular topic, user, pattern, or other parameter. For a substantial cost, Twitter makes available a 'firehose' of all public Tweets; but, companies with access must have infrastructure for collecting, storing, sharing, and removing tweets by suspended accounts for vast numbers of tweets to make use of this stream. Twitter shuts down or suspends accounts that appear to be bots or that violate Twitter policies (Thomas et al, 2011); which means historic data is often not available. The impact of this policy can be severe; e.g., in some cases up to $25 \%$ of a country's geo-tagged tweets may be dropped (Wei \& Carley, 2015). Thus, when a disaster occurs, it may not be possible to "go back in time" using Twitter to figure out where people are likely to be.

Twitter's community and conventions have been extensively studied (Honeycutt \& Herring 2009; Marwick \& Boyd 2011; Weller et al., 2014; Gaffney \& Puschmann 2013; van Dijck 2013; Kumar, Morstatter \& Liu 2015). The twittersphere is often a vibrant social and political discussion space with unique communities, ${ }^{2}$ although much of its adoption seems driven by people's interest in following the Twitter accounts of celebrities (Hargittai \& Litt, 2011). In this ecosystem, corporate accounts try to engage users, bots spam people (Donath, 2007; Thomas et al 2011), users follow celebrity intrigue, participate in political discussions, and harrass others (Donath, 2007; Thomas et al., 2013). Twitter activity is a biased representation of human activity (Weller et al., 2014). In the US, it is biased towards urban, affluent populations (Hecht \& Stephens 2014; Malik et al 2015; Mislove et al. 2011). Tweeter demographics vary internationally (Poblete et al 2011), impacting inference (Cohen \& Ruths, 2013), and resulting in mis-predictions concerning elections and epidemics. The Twitter community has its own norms and practices that are not a generalizable representation of community norms (Tufekci, 2014; Ruths \& Pfeffer, 2014); therefore, it may not be good for assessing social network mechanisms (Shalizi \& Thomas, 2011). However, it is good for identifying general trends, issues of general relevance, rapidly spreading information, and possibly for predicting future trends such as movie box office success (Asur \& Huberman, 2010; Wong, Sen \& Chiang, 2012; Gayo-Avello, 2012). Since Twitter supports collecting vast amounts human data with relatively little effort, it has become enormously popular as a sensor. For disaster management, the questions is: Will Twitter data will be useful for planning and early warning, and if so, how it should is it best collected?

\section{2 - Twitter Usage in Indonesia}

Indonesians were early adopters of Twitter and are among the most prolific Twitter users. In 2010, comScore report ranked Indonesia as the country with the highest Twitter penetration, with $20.8 \%$ of the Internet-using population visiting Twitter in the month of June. ${ }^{3}$ By 2012 the

\footnotetext{
${ }^{2}$ See, e.g., http://www.buzzfeed.com/jwherrman/weird-Twitter-the-oral-history

${ }^{3}$ http://www.comscore.com/Insights/Press_Releases/2010/8/Indonesia_Brazil_and_Venezuela_Lead_Global_Surge in Twitter_Usage last accessed - Feb. 2015.
} 
Indonesian Twitter population reach 29.4 million, the fifth largest in the world. ${ }^{4}$ In 2013 Cable News Network (CNN) dubbed Indonesia the "Twitter nation" (Lim, 2013). As of 2014, Indonesia is the fifth most tweeting country, Twitter reports approximately 29 million Indonesian users, with $2.4 \%$ of the 10.6 billion Twitter posts made between January and March of 2014 coming from Jakarta. ${ }^{5}$ In 2012, the 29.4 million Twitter users represented $11.9 \%$ of Indonesia's total population of 247 million. ${ }^{6}$ In 2012 the World Bank estimated the Indonesian Internet-using population at $15.4 \%,{ }^{7}$ meaning that $77.3 \%$ of Indonesian Internet users were using Twitter. For city-level geolocalized tweets, Jakarta was the most active city in the world, accounting for $2 \%$ of the total volume, with Bandung coming in sixth. Indonesia has the highest tweets/user ratio at 1,813.53, ahead of Japan $(1,617.35)$ and Brazil $(1,370.27)$ (Poblete et al, 2011).

\section{3 - Sociocultural Context}

Between the migration of millions of young Indonesians from rural areas to the cities, and the rapid adoption of social media in these urban areas, Indonesia has witnessed major socio-cultural changes in the last two decades (Miguel et al, 2006). Although less than 1\% of users had internet access in 1998 it was used to diffuse critical information; e.g., when Suharto shut down other media, information spread through the internet and radio led to his downfall (Basuki 1998; Hill \& Sen, 2000). Today, the internet and social media are strongly integrated into the Indonesian sociocultural landscape. Indonesian's refer to Internet cafés, and sometimes the internet itself, as warnet, a contraction of 'warung Internet,' named after a simple place for lower-middle and lower classes to buy snacks or meals and congregate while eating (Lim, 2003). These warnets provide inexpensive, and social, internet access outside of universities. Like pubs in England and America, people go to the warnet to socialize, get access to news, and pass on news both face-to-face and through social media. The rapid adoption of social media has pervaded all aspects of Indonesian life, and led to cultural changes and new behaviors. Examples include, cell phones being used to communicate with the supernatural world through a channel for ghostly communication (Barendregt \& Pertierra, 2008), evolving images of women and public intimacy (Brenner, 1999), new internet-based economic concerns (Couldray \& Curran, 2000; Lim, 2003), and public attention to fraud (Setiyono \& McLeod, 2010; The Asia Foundation, 2014). Although Internet and Twitter usage are concentrated in Jakarta and Java's urban centers; their use is high in rural communities. Much internet access is through mobile technology. By August 2013, 64\% of the iPhone users in Indonesia, tweeted, as compared to $36 \%$ in the United States. ${ }^{8}$ Most of the Indonesian tweets concern sports or local news; e.g., in 2011, approximately $20 \%$ of all tweets in Indonesia concerned soccer, $11 \%$ local events, $5 \%$ each for news, TV shows and music. ${ }^{9}$ Among the most followed Twitter sites are @Indonesia, @IndonesianIdol, @ BNI46 (Official Twitter of Bank Negara Indonesia), followed by the sites for various politicians and soccer stars. This usage pattern suggests that sites sending alerts need to be mobile friendly, and that alerts sent by

\footnotetext{
4 http://semiocast.com/publications/2012 $07 \quad 30$ Twitter_reaches half_a billion_accounts_140m in the US last accessed - Feb. 2015.

${ }^{5}$ https://www.techinasia.com/indonesia-social-jakarta-infographic/ last accessed - Feb. 2015.

6 http://data.worldbank.org/indicator/SP.POP.TOTL last accessed - Feb. 2015,

${ }^{7}$ http://data.worldbank.org/indicator/IT.NET.USER.P2 last accessed - Feb. 2015.

${ }^{8}$ Sept 2013 - http://venturebeat.com/2013/09/26/Twitters-global-mobile-reach-36-in-u-s-8-in-germany-64-inindonesia/ last accessed - Feb. 2015,

${ }^{9}$ https://wiki.smu.edu.sg/digitalmediaasia/img_auth.php/5/56/Trending_Topics_Twitter_Indonesia_2011_Saling_Sil ang.jpg last accessed - Feb. 2015.
} 
celebrities or sport-teams will reach a larger audience. It also suggests that due to its use as a social device, information sent on Twitter will reach the larger non-tweeting audience.

Information and communication technologies are widely used in disasters and their aftermath in Indonesia. During the 2004 tsunami in Aceh, community radio stations disseminated information and broadcast messages to help survivors recover from grief, after large parts of the media infrastructure were destroyed (Birowo, 2013). Similarly, community radio was used in West Sumatra when a 5.8 magnitude earthquake struck in March 2007. Community radio stations disseminated information from the Indonesian Meteorological and Geophysical Agency to reduce the impact of rumors about an impending tsunami and another earthquake. The Community Radio Network of West Sumatra "dropped volunteers in the affected areas to set up emergency radio. Because their station budgets had no available funds, volunteers had to use their own money." Radio stations broadcast nazam-s, traditional Acehnese poems, consisting of religious messages to help survivors recover from grief. This spontaneous Indonesian response used available technology to spread information when other infrastructure was destroyed (Birowo, 2013). Prior to the February 13, 2014 Mount Kelud eruption, government agencies posted warnings and geological updates on Twitter, and community groups and individuals spread information (Anggunia \& Kumaralalita, 2014). After the eruption killed 16, community radio spread messages of support, and key information. These efforts are complicated by the Twitter stream being cluttered with non-disaster information thus requiring topic modeling to extract relevant data. New disaster-focused topic models show promise, and have been tested given Indonesian earthquake Twitter data (Kireyev et al., 2009).

Currently, social media plays a limited role in planning and early warning. For example, a system for testing evacuation routes following earthquakes based on tweets has been tested with respect to the Sumatra earthquake (Ishino et al., 2012). In major cities there appear to be sufficient geo-tagged tweets to make route tracking feasible. While government officials turned to Twitter after the Mt Sinabung eruptions, the communication was not as effective as it could have been as failures in inter-agency coordination and the lack of clear cross-jurisdictional communication created challenges that the technology alone could not overcome (Chatfield et al., 2014; Chatfield et al., 2013). As of Feb 2015, many of these difficulties remain; yet, Twitter is currently being used as part of the disaster management process.

The Australian University of Wollongong's SMART Infrastructure Facility and DKI Jakarta Regional Disaster Management Agency (Badan Penanggulangan Bencana Daerah - BPBD DKI Jakarta, under a Twitter Data Grant, launched project Peta.Jakarta. This system employs a realtime mapping system that uses tweets to understand how floods are moving and what areas are hardest hit. ${ }^{10}$ In addition, Indonesian government agencies banded together to create a Twitterbased early warning system for Tsunamis - Indonesia Tsunami Early Warning System (InaTEWS). The National Disaster Management Agency (NDMA) is the lead agency operating InaTEWS to detect, analyze, simulate, and disseminate disaster information on earthquake, tsunami, and severe weather. This dissemination goes through multiple mediums including Twitter. Chatfield \& Brajawidagda (2013) examined InaTEWS and concluded that critical information was not getting to officials soon enough, and that the general public was not supported. In InaTEWS, NDMA works closely with the Meteorological, Climatological and Geophysical Agency of Indonesia (BMKG). BMKG issues three types of warnings. The first early tsunami warning can be issued during the first 5-7 minutes after the occurrence of an earthquake. The

${ }^{10}$ https://gigaom.com/2014/12/04/indonesia-is-mapping-jakarta-floods-in-real-time-using-Twitter/ last accessed Feb. 2015. 
second warning either confirms or cancels the first warning and can be issued within 10-30 minutes. The third warning is issued after the coastal observation of a tsunami and can be issued between 30-60 minutes. These early tsunami warnings are intended to inform government agencies; they are not issued directly to the public. However, BMKG is widely followed by the public on Twitter and its warnings are retweeted (e.g. in 2012 on average BMKG warnings were retweeted 2000 times). By 2012 BMKG had over 300,000 Twitter followers, and today has over 1 million (see @BMKGIndonesia). Other key agencies that are part of this early warning system are also widely followed; e.g., the police - Polri - @NMTCPolri, the national agency for disaster management - Badan Nasional Pananggulangan Bencana - @BNPB_Indonesia, Kominfo, the Pacific Tsunami Warning Center, and @NewEarthquake. Twitter alerts increase lead time, but are currently best used in conjunction with traditional warning systems and news (Chatfield and Brajawidagda, 2013). This suggests that the technologies in this issue will need to be integrated with InaTEWS and BMKG.

\section{4 - Data Collection}

If Twitter data is to be used for planning and early warning it is important that it be collected in a systematic fashion and that the biases be well understood. In this section we ask, what are the strengths and limitations of different data collection strategies as they relate to issues of coverage, spatio-temporal patterns, and identification of opinion leaders. Unless the full firehose is purchased, the data stream used in a disaster management tool will be a sample. The goal from a disaster management perspective is to collect those tweets coming from the region of interest, by the population in that region. Whether it is important to focus on tweets related to disaster management (and so, minimize the number of tweets collected about general politics, sports and entertainment) is in question. While the ideal is collecting all and only the tweets from a region of interest and its population; the reality is that the Twitter API and the way people use Twitter make this impossible. For example, there is a parameter for "country" in the tweet metadata, but it is user-reported rather than tagged by Twitter, and is not a parameter by which one can make requests to the API; however it can be used to post-process the tweets and remove unwanted tweets from the data collection. Thus, we considered five different ways of sampling Twitter data where we varied: the cap on the number of tweets that could be collected $(1 \%$ or $10 \%$ of the tweets in the world), the use of disaster related terms, and the size of the bounding-box which is the "rectangle" on a map from within which the tweets are sent (Padang or Indonesia). We find that the data collection strategy will impact the estimates of the coverage, geo-temporal pattern, and opinion leaders.

We considered five different collection strategies (CS): CS1 - Decahose Indonesia: a sample of $10 \%$ of all tweets at that time in the world was collected and then only those tweets that were geo-tagged to lie in Indonesia were retained; CS2 - Decahose Padang: a sample of 10\% of all tweets at that time in the world was collected and then only those tweets that were geo-tagged to lie in Padang were retained; CS3 - Streaming Sample geo+terms Indonesia: using the streaming API a sample of tweets was collected such that each tweet was either from someone tweeting within the bounding-box around Indonesia and/or contained selected disaster related key words and the total number of tweets collected did not exceed $1 \%$ of all tweets at that time worldwide; CS4 - Streaming Sample geo+terms Padang: using the streaming API a sample of tweets was collected such that each tweet was either from someone tweeting within the bounding-box around Padang and/or contained selected disaster related key words and the total number of tweets collected did not exceed 1\% of all tweets at that time worldwide; CS5 - Streaming Sample geo Padang: using the streaming API a sample of tweets was collected such that each tweet was from 
someone tweeting within the bounding-box around Padang and the total number of tweets collected did not exceed $1 \%$ of all tweets at that time worldwide.

The full details of the infrastructure and criteria used to gather the CS3, CS4 and CS5 samples from the streaming API is described in Landwehr et al. (forthcoming - this issue). The approach used is replicable using other infrastructure. These three different data streams were captured by three different users. In all cases, bounding-boxes for the minimum size enclosing the desired region were used: Indonesia (southeast corner -9.5, 95.0 and northwest corner 6.0, 141.0), Padang $(100.25,-1.05 ; 100.5,-0.75)$. For CS3 \& CS4, tweets were collected using the bounding-box and a set of terms in Bahasa (Indonesian) and English chosen from a list compiled by the researchers (in consultation with Indonesian colleagues) that includes the names of 53 Indonesian locations and disaster-related words identified in prior Twitter disaster studies that focused on needs - food, water, shelter, safety, lost children or parents, and corruption, and the names of prominent Indonesian organizations and citizens. Tweets associated only with entertainment celebrities or sports were filtered out. This will bias the sample towards tweets about locations, politics, and disasters, which is acceptable for disaster management.

These strategies reflect limitations of the way in which Twitter provides data to end users. The decahose (10\%) cannot be focused on one area. The decahose is an overarching archival sample, was made available to researchers at our institution, and contains over 100 million tweets (O'Connor et al., 2010; Einstein et al., 2014). The streaming API cannot be used to collect more tweets than $1 \%$ of all tweets in the world at the time of collection. These are strategies for data collection available to those planning for disasters and creating early warning systems. By comparing these strategies we are able to address: is the $10 \%$ generic or $1 \%$ targeted a better sample for disaster planning and is an Indonesian wide or city specific (Padang) sample better for disaster planning.

Each of these five data collection strategies has pro's and con's. The purely random samples provided by the decahose better represents Twitter's population as a whole (CS1 \& CS2). They can be useful for understanding how any particular facet of Twitter - presence in a country, use of language, use of particular hashtags - exists relative to the rest of the Twittersphere. This data can be good for establishing the temporal dynamics; but, is too generic to mine detailed facts about a specific incident. A random decahose sample will be marginally useful to first responders, but a $1 \%$ directed sample will be more useful as it focuses attention on the issues of concern.

The decahose is less useful, particularly for less major cities, as even a $10 \%$ random sample from the world will not provide enough data relevant to the region or a given city. The difference between CS2 and CS5 is when in the data collection process geo-tagging is used. For CS2, a sample of $10 \%$ of the tweets in the world at that time are selected at random and then post-facto only those with geo-coordinates in Padang are selected for use. This approach guarantees that each tweet can be placed at a specific latitude and longitude on the map. For CS5, all tweets from a bounding-box that includes Padang are collected but if the number of tweets from those in Padang during that time exceeds $1 \%$ of the tweets in the world then Twitter caps the number that are collected. This approach guarantees that the tweets are from within the bounding-box; however, they may not have a latitude and longitude and so may not be placed at an exact location on a map. Even when only those with a specific latitude and longitude are retained, the result is that CS5 generates more tweets in Padang than CS2. As Table 1, suggests a directed collection of tweets using the streaming API using only a bounding-box provides the highest coverage of what is being tweeted in that region. As will be further discussed in this paper, this CS5 collection strategy 
appears to be best for disaster planning and early warning; however, as will be seen, care must be taken to overcome the biases in the data.

Nevertheless, just in terms of volume two questions remain: First, will this $1 \%$ data collection be sufficient for planning and early warning? Second, will this $1 \%$ data collection be sufficient when a crisis occurs to track people during the event and in the immediate aftermath. To answer the first question, we need to understand what fraction of tweets in the region are actually being collected. For example, in Padang there were 1,024,906 people circa 2014. If even $15 \%$ have Twitter accounts (national average was 11.9 in 2012) then 153,736 will have sent a tweet. However, of those on Twitter only about 1 in 1000 remain active, which mean only 154 of these people will be monitoring and sending at any time. The average number of tweets per minute is currently at 350,000 which means there are 3,500 in the $1 \%$ feed. Even at three tweets a minute these active users could not generate enough tweets to exceed the $1 \%$ of all tweets worldwide in one minute. This analysis suggests that indeed, the CS5 strategy is generally collecting most, if not all of the tweets in the Padang region. For larger regions, the data collectors might want to divide the region into sub-regions and use the CS5 strategy for each sub-region separately.

To answer the second question, we need to understand how much the number of tweets in the region will increase during a disaster. In general, when a disaster occurs the number of tweets that mention the disaster, the region where it occurs, or the response effort increases - often quite dramatically; e.g., using both regional location and disaster terms for Typhoon Yolanda there were fewer than 100,000 tweets in the week prior to the event and over 500,000 during the first four days as the typhoon came in and its immediate aftermath. As a general rule we few regional disasters will reach that $1 \%$ limit for tweets from the region. Most of the tweets vis a disaster come from outside the region of interest; e.g., in our study of the Philippines we found that most tweets referring to Yolanda were not from the Philippines. For those tweets from within the region, they won't exceed the 1\% except for extremely large regions e.g., major and mega-cities. For Padang, for the number of tweets from Padang to exceed the $1 \%$ of tweets worldwide, not only would the frequent tweeters have to send at least three tweets a minute but in addition the large numbers of infrequent Padang tweeters who tweet between 10 and 1000 tweets a week would have to start tweeting.

As noted, for large regions those collecting tweets can extend the coverage by using a team to collect multiple sets of tweets. Such multiple samples, however, still do not provide perfect coverage. Further, there are many possible biases that occur during Twitter collection. Morstatter et al. (2013) have shown that there are serious concerns about the reliability of the Twitter Search API, which returns a non-representative sample of high-volume data. However, as this is the source that would be available for monitoring in disaster situations, we view it as an appropriate stream to describe and analyze. We now discuss some of these limitations.

The Twitter API, circa 2012-2015, places a number of restrictions on collection that further bias the data. It is possible, using the API, to request tweets with a geolocation that falls within the border of Indonesia using geo-spatial bounding-boxes. There are two difficulties here. First, less than $10 \%$ of all tweets are geo-tagged (Morstatter et al., 2013) with latitudes and longitudes. Thus, bounding-box selection only will bias the sample towards users unconcerned with broadcasting their specific location and using smartphones with a geo-positioning system (GPS). Such Twitter users may be systematically different from others. Second, the Twitter API provides tweets from predefined polygons such that even when a bounding-box is the only selection criterion, tweets with geo-tags that fall in overlapping polygons, but not inside the bounding-box may appear in the collected data stream. Thus, it is necessary to filter the returned tweets to include 
only those falling within the region of interest; e.g., setting a box to cover Indonesia and then excluding those tweets falling within Malaysia and other countries with land in the bounding-box or with overlapping polygons. Finding whether a point falls inside or outside of a complex polygon is a mathematically complex and computationally difficult problem, but fortunately one that has been studied extensively, and for which the best solution is easily available to implement. We carried out such a filtering using existing tools for CS5.

When the bounding-box plus terms strategies were used, there were zero geo-tagged tweets returned for Indonesia (CS3) during some periods, and only a small handful for Padang (CS4). Though highly unusual, it is not impossible particularly for that collection period that coincided with the 2014 Iquique earthquake in Chile. This earthquake, and the resulting tsunami, were the topic of a great deal of Twitter discussion in Indonesia and on the Internet in general (see Landwehr et al., forthcoming). During this period, the number of tweets with these keyword were far greater than the number of tweets within the bounding-box, resulting in the sample being biased to those tweets outside the bounding-box.

Unless the geo-tagged tweets are spoofed or falsely tagged, they are guaranteed to be in Indonesia so are more reliable; however, there is a far larger volume of tweets with Indonesia as the user-reported country location. This creates a trade-off between volume and accuracy given these two ways of identifying tweet location. For disaster management, this suggests that there is value in doing two data collections: one focused exclusively on the bounding-box and one using both terms and a bounding-box. In this case, though, care will be needed to de-duplicate the tweets and to remove those that are clearly not in the region. There is an app called "UberTwitter" (http://www.uberTwitter.com/) which, for the users who use it, has a service to set the userreported "location" field to their current geocoordinates prefaced by "ÜT:". This is distinct from the "country location" field which can be set to anything e.g., "in your heart." We used character matching to extract all such cases from our data set. As it turns out, $0.71 \%$ of tweets have this UberTwitter tag and accompanying geocoordinates, which is considerably less than the $3.17 \%$ of tweets from the Streaming API and $1.45 \%$ of tweets from the firehose reported by Morstatter et al. (2013) but still not insignificant. We hereafter consider the UberTwitter coordinates as the geotags. While UberTwitter users are a subset of users who differ in systematic ways (such as using UberTwitter), the idea that the tweets for which we have precise geocoordinates are a minority that are systematically different is the same for Twitter's geo-tags and for those of UberTwitter. Hence our method of investigating systematic differences and the nature of subsets applies even if actual geo-tagged tweets would have their own differences.

For the Twitter API, 'language' is not a parameter by which one can make requests, even though the tweet metadata contains both the tweet language and the user's profile language (both of which users must choose, and this information is included with every tweet). In the large Indonesian population centers, where Twitter is predominantly used, many speak and tweet in English; e.g., the most common users are under 40 and the most likely to speak and tweet in English. Selecting only tweets in Indonesian misses this community.

The consequences of these data collection strategies for the number of tweets and users and the nature of the tweets is shown in Table 1, as is our recommendation for best usage. Clearly, any collection strategy can result in a prodigious amount of data. Note, however, that the average number of tweets and users per day is quite different. So too, is the dominant day and hour. This summary indicates that coverage is better using the API; further, the use of terms means that the tweets may be dominated by those not in the region of interest. 
The key finding across data collection strategies are these: While access to the decahose may provide more tweets overall, the number of those tweets that are of interest for a specific region or disaster is low. Targeted collection using the 1\% API can identify most tweets of interest and so is the preferred data collection strategy. Strategies such as CS3 and CS4 that select tweets using specific terms can be swamped by tweets from outside the region of interest; hence it is better to first select on the region using bounding-boxes and then afterwards, subsample based on the terms of interest. Extracting relevant data takes substantial post-processing focusing on the language and the geographic information. This problem is reduced by a pure bounding-box strategy (CS5), but not eliminated due the Twitter API pulling data based on overlapping polygons. For disaster management, initial collection by the region (bounding-box) has the advantage that it provides the largest corpus of data from the region of interest; however it will be biased as it will not include tweets from the region that are not known to be in the bounding-box. For small regions, such a strategy may get you near perfect coverage of the geo-tagged tweets. Finally, the overall profile for how twitter is used may appear quite different under the collection regimes. Multiple strategies will provide a more comprehensive view. The remainder of this paper follow these best uses and uses a sample from CS3 for the week of June 1-7, 2014 when there was no external to Indonesia disaster, and CS5.

\begin{tabular}{|c|c|c|c|c|c|}
\hline \multicolumn{6}{|c|}{ Table 1. Differences by Data Collection } \\
\hline Metric & $\begin{array}{c}\text { CS1 } \\
\text { Decahose } \\
\text { Indonesia }\end{array}$ & $\begin{array}{c}\text { CS2 } \\
\text { Decahose } \\
\text { Padang }\end{array}$ & $\begin{array}{c}\text { CS3 } \\
\text { API Indonesia } \\
\text { Box \& Terms }\end{array}$ & $\begin{array}{c}\text { CS4 } \\
\text { API Padang } \\
\text { Box \&Terms }\end{array}$ & $\begin{array}{c}\text { CS5 } \\
\text { API Padang } \\
\text { Box }\end{array}$ \\
\hline Start Time & $1 / 1 / 2011$ & $1 / 1 / 2011$ & $2 / 24 / 2014$ & $2 / 24 / 2014$ & $11 / 05 / 2014$ \\
\hline End Time & $9 / 28 / 2014$ & $9 / 28 / 2014$ & $6 / 16 / 2014$ & $6 / 16 / 2014$ & On-Going \\
\hline $\begin{array}{l}\text { Tweets } \\
\text { Collected }\end{array}$ & $66,400,000$ & 431,971 & $678,640,600$ & $12,187,189$ & $52,286,500$ \\
\hline $\begin{array}{l}\text { Day with most } \\
\text { tweets (average) }\end{array}$ & Sunday & Sunday & Sunday & Tuesday & Wednesday \\
\hline $\begin{array}{l}\text { Hour with most } \\
\text { tweets (average) }\end{array}$ & $8: 00$ PM & 9:00 PM & 5:00 PM & 9:00 AM & 9:00 PM \\
\hline $\begin{array}{l}\text { Ability to find } \\
\text { networks of } \\
\text { users }\end{array}$ & Low & Low & Medium & Medium & High \\
\hline Topics & $\begin{array}{l}\text { Trending } \\
\text { topics - sports, } \\
\text { entertainment }\end{array}$ & $\begin{array}{l}\text { Trending topics - } \\
\text { sports, } \\
\text { entertainment }\end{array}$ & $\begin{array}{l}\text { Term related } \\
\text { topics }\end{array}$ & $\begin{array}{l}\text { Term related } \\
\text { topics }\end{array}$ & $\begin{array}{l}\text { Local topics - } \\
\text { politics, sports, } \\
\text { entertainment }\end{array}$ \\
\hline Coverage & $\begin{array}{l}\text { Proportional to } \\
\text { Twitter usage }\end{array}$ & $\begin{array}{l}\text { Proportional to } \\
\text { Twitter usage }\end{array}$ & $\begin{array}{l}\text { Driven by topics } \\
\text { with regional } \\
\text { focus }\end{array}$ & $\begin{array}{l}\text { Driven by } \\
\text { topics with } \\
\text { regional focus }\end{array}$ & $\begin{array}{l}\text { Dominated by } \\
\text { region of interest }\end{array}$ \\
\hline Key issue & Low coverage & Low coverage & $\begin{array}{l}\text { Many users } \\
\text { outside region }\end{array}$ & $\begin{array}{l}\text { Many users } \\
\text { outside region }\end{array}$ & $\begin{array}{l}\text { Only geo-tagged, } \\
\text { few verified or } \\
\text { news }\end{array}$ \\
\hline Best use & $\begin{array}{l}\text { Temporal } \\
\text { dynamics }\end{array}$ & $\begin{array}{l}\text { Comparison with } \\
\text { world }\end{array}$ & $\begin{array}{l}\text { General country } \\
\text { profile }\end{array}$ & $\begin{array}{l}\text { Concern with } \\
\text { issue }\end{array}$ & $\begin{array}{l}\text { Local networks } \\
\text { and geo- } \\
\text { distribution }\end{array}$ \\
\hline
\end{tabular}

\section{5 - Characterizing Tweets for Disaster Management.}

We now examine the biases in the data, for Indonesia in particular, with respect to coverage, spatio-temporal patterns, and the identification of local opinion leaders. We note that the nature of the bias is a reflection of the way in which Twitter is used. To illustrate these issues we describe 
results we use various data collection strategies; however, our large investigation reveals that often similar issue arise regardless of the collection strategy. The key insights are:

- News sources and verified users provide a consistent and steady output, but are too sparse to be the focus of volume monitoring.

- For identifying which tweets come from users in Indonesia, geotags and user-reported country location present a trade-off between accuracy and volume.

- As with most Twitter data, activity is highly skewed regardless of subset, with the majority of users sending only one tweet, and the majority of tweets coming from a minority of users.

- Frequent tweeters are often bots or commercial accounts, and frequent tweets are often spam.

- The plurality of tweets come from users whose profile language is English, but whose tweets are in Indonesian, indicating a bilingual population.

- Evenings (around 8pm) and weekends (Saturday and Sunday) ${ }^{11}$ are the most active tweeting times, suggesting that much tweeting is a leisure activity.

- The users with the most mentions, and hashtags with the most volume, relate to celebrities, entertainment, politics, news, and music.

- Geotagged activity is concentrated in cities, coastal areas, and universities, demonstrating insufficient Twitter coverage for remote and rural areas.

\section{1 - Coverage}

We examine three basic aspects of the collected data: volume, usage and language. For this, we use CS3, as the API provides better coverage in terms of volume. Note, in a disaster the CS3 strategy may yield more tweets commenting about the disaster than from the disaster area (as we found in two API collections during the Chilean earthquake). We chose the given period as it is a fairly normal period (no major external disasters), we had full coverage (no server outages or Twitter breakages), and it is a sufficiently large set that general trends can be assessed.

\subsection{1 - Volume}

Table 2 summarizes the volume of tweets collected in a single week using the CS3 strategy. For the three classes of users, we see that although News and Verified Users are rare, they are tweeting at a higher and less variable rate than others. There are three key implications for disaster management. First, the news as an authoritative voice is well and consistently represented. Second, much Twitter data is biased to issues not related to disaster or to Indonesia as signaled by the large number of languages and locations. Third, the number of verified users, and their tweets is extremely small but highly followed, suggesting they could spread warnings. Fourth, although verified and news tweeters are known to not be bots, there are too few that are geo-tagged to make them a reliable gage of where the population is or its concerns. Thus, those disaster planning who wish to use tweets to track disaster response or attention to early warnings, cannot rely on verified users.

Not surprisingly, the majority of tweets are in Indonesian or English. Of these tweets, very few have either geo-tags or locations mentioned. However, where the location is indicated most are in Indonesia. Note that even though most of the users in this sample list English as their language, most are tweeting in Indonesian (see section 5.1.3, and Table 3). Also worth noting is that a substantial number of users tweet in more than one language, 330,040 (9.96\%), suggesting a population of potential volunteer translators

\footnotetext{
${ }^{11}$ Unlike in some predominantly Muslim countries where the workweek is from Sunday to Thursday (as Friday is the communal Day of Assembly in Islam), the Indonesian workweek is from Monday to Friday
} 
A data collection strategy that pulls data using a bounding-box and terms will generate data whose center is in the region of interest and in the language of that population; however, the data will not be exclusively from that region. Thus, the data will require substantial data cleaning. The second implication is that there is likely to be a significant Twitter population that is bi- or possibly multi-lingual (as is evidenced by both the multi-lingual tweets and the fact that the profile and tweet language are different). Such individuals may be mobilized to help get information to multiple linguistic communities.

\begin{tabular}{|c|c|c|}
\hline \multicolumn{3}{|c|}{ Table 2. Overall volume of tweets and users for Indonesia for a typical week } \\
\hline Subset & Tweets & Users \\
\hline All tweets & $13,670,165$ & $3,312,550$ \\
\hline By any source per day & $2,143,260$ (4,054,835 std. dev. $)$ & 12,856 \\
\hline By news source per day & 1,509 (4,106 std. dev.) & $6(10)$ \\
\hline By verified source per day & 6,999 (16,130 std. (dev.) & $12(32)$ \\
\hline Tweets in Indonesian* & $8,530,352(62.40 \%$ of all tweets $)$ & $1,515,698$ (45.76\% of all users) \\
\hline Tweets in English* & $4,272,018$ (31.25\% of all tweets) & $1,732,130(52.29 \%$ of all users $)$ \\
\hline $\begin{array}{l}\text { Tweets with profile language } \\
\text { Indonesian* }\end{array}$ & $3,968,271(29.02 \%$ of all tweets) & $640,466 * *(19.33 \%$ of all users $)$ \\
\hline $\begin{array}{l}\text { Tweets with profile language } \\
\text { English* }\end{array}$ & $8,900,104$ (65.11\% of all tweets) & $2,382,708 * *(71.93 \%$ of all users $)$ \\
\hline $\begin{array}{l}\text { Tweets with user-reported } \\
\text { country location }\end{array}$ & 574,484 (4.20\% of all tweets) & 62,698 (1.89\% of all users) \\
\hline $\begin{array}{l}\text { Indonesia as user-reported } \\
\text { country location* }\end{array}$ & $\begin{array}{l}401,185 \text { ( } 2.93 \% \text { of all tweets, } 69.83 \% \\
\text { of tweets with user-reported country) }\end{array}$ & $\begin{array}{l}51,264(1.55 \% \text { of all users, } 81.76 \% \\
\text { of users with user-reported } \\
\text { country) }\end{array}$ \\
\hline Geo-tagged tweets (UberTwitter) & $97,308(0.71 \%$ of all tweets $)$ & $21,746(0.66 \%$ of all users $)$ \\
\hline Indonesian coordinates* & $\begin{array}{l}90,768 \text { ( } 0.66 \% \text { of all tweets, } 93.28 \% \\
\text { of geo-tagged tweets) }\end{array}$ & $\begin{array}{l}20,089 \text { ( } 0.61 \% \text { of all users, } 92.38 \% \\
\text { of users with geo-tagged tweets) }\end{array}$ \\
\hline
\end{tabular}

*There are three distinct potential ways to identify users in Indonesia: a geotag with coordinates in Indonesia (none in our data), a geotag from the UberTwitter app with coordinates in Indonesia, or Indonesia being the userreported country location. Very few tweets have both user-reported country location and an UberTwitter geotag, and for the vast majority of these, the two fields give the same location.

\subsection{2 - The Users}

The distribution of tweets per user is shown in Figure 1, where we see that, like most Twitter data sets, the majority of users hardly tweet, and a small number tweet excessively (the peculiar jump in all these distribution plots around 15 tweets is most likely a function of the Twitter API, rather than a pattern in tweeting behavior).

For example, 1,660,575 users have one tweet, whereas the top user had 33,760. The top four users $^{12}$ in our data from this time period have since had their accounts suspended by Twitter, which suggests that they may have been bots. The top user from our data whose account is still active is @ Aquafloater, with 9,080 tweets over the week. This account is a commercial one, tweeting out only links with hashtags of a magazine. The distribution suggests two things: first, there are highvolume individuals with a following and a disproportionate impact in spreading messages, and second, there are a large number of users that can be activated in times of crisis. For disaster management this distribution means that the identification of influential users or opinion leaders should take into account tweet frequency, in part, as low frequency users may not be on-line at the

\footnotetext{
$12 @$ BANDUNG_24JAM (33,760), @AllFoodAlltheTi $(18,557)$, @BOTartri2 $(10,754)$ and @BOTartri1 $(10,502)$.
} 
critical time. It also means that a few users will have a disproportional impact in spreading the message.

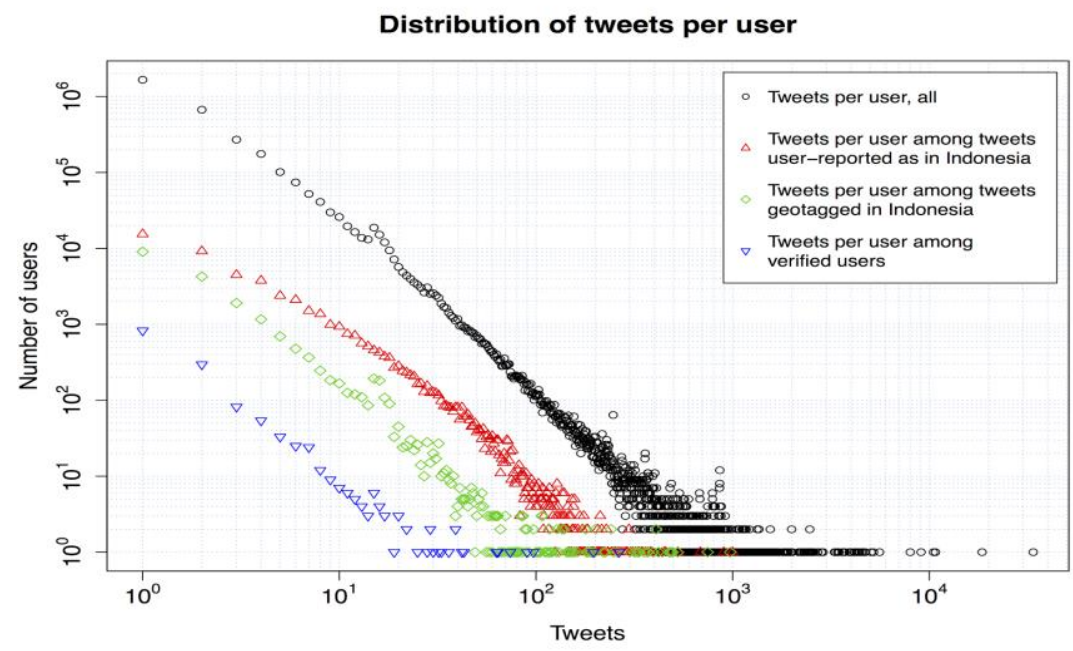

\section{Figure 1. Distribution of tweets by type of user.}

\subsection{3 - Language}

Although Indonesian/Malay (specifically Bahasa Indonesian/Bahasa Malay) is the official language, over 700 languages are spoken in Indonesia. ${ }^{13}$ In our data, however, only 52 languages are used in tweets from users with 62 represented profile languages; however, the most common are Indonesian, English and Tagalog. In Table 3, using a week of CS3, we see that the tweets are predominantly in Indonesian, then English, then Tagalog (the language of the Philippines). Tagalog is surprisingly prevalent; it may be from a small number of affluent Filipino professionals in Jakarta ${ }^{14}$ from the bounding-box for Indonesia overlapping regions associated with Malaysia and the Philippines, or from key terms being shared across the region. Although not shown, there is a similar distribution across the users. Further, the percentage of users who tweet in Indonesian is smaller than the percentage of tweets in Indonesian, meaning that the users who tweet in English are disproportionately represented among more active tweeters suggesting that warning in English will spread disproportionately fast. Users who self-report their location as Indonesia are far less likely to send out tweets in Indonesian than are users who have geo-tagged tweets with Indonesian coordinates. In a typical week, CS3, 63\% of users tweet in the language of their profile and $330,040(9.96 \%)$ have tweets in more than one language; suggesting a high level of bi-lingual users. Three or more languages are used by 74,661 users, although excessive language variety are likely spam (e.g., one since-suspended account had tweets in 40 languages). The bilingual or multilingual users can be identified via Twitter prior to disasters, and then reached out to help spread early warnings and to support the relief effort. When the profile language is Indonesian, the user will have a strong predilection to tweet in Indonesian $(82.79 \%)$. However, if the profile language is English, the user is not as likely to tweet in English; $58.47 \%$ of users with English-language profile tweet in English, but $33.42 \%$ tweet in Indonesian. ${ }^{15}$ Considering only individuals with geotagged tweets, we find that users who tweet in Indonesian only are the majority at $71.23 \%$. This is

\footnotetext{
${ }^{13}$ Bahasa Malay and Bahasa Indonesian are the same language, and the official language of Malaysia and Indonesia.

${ }^{14}$ http://web.archive.org/web/20140206020350/http://www.thejakartapost.com/news/2008/03/28/goodneighbors.html

15 Of the approximately $3.31 \mathrm{~m}$ users, $2.88 \mathrm{~m}$ only have one profile language and tweet in one language, and about 325,000 have two languages. We double-count these, and similarly multiply-count the languages of the remaining users as they are negligible.
} 
even more true for CS1, CS2 and CS5. Despite English being considered a prestige language in Indonesia (Lauder, 2008), the Twitter-using population still prefers Indonesian and will be the focus of disaster-related communication.

Table 3. Tweet volume by tweet language for a typical week from CS3.

\begin{tabular}{|c|c|c|c|}
\hline Tweet Language & Indonesian & English & Tagalog \\
\hline Tweets (\% of all tweets) & $\begin{array}{l}8,530,352 \\
(62.40 \%)\end{array}$ & $\begin{array}{l}4,272,018 \\
(31.25 \%)\end{array}$ & $\begin{array}{l}158,797 \\
(1.16 \%)\end{array}$ \\
\hline $\begin{array}{l}\text { Tweets with user-reported country location ( } \% \text { of all tweets } \\
\text { with user-reported country location) }\end{array}$ & $\begin{array}{l}376,787 \\
(65.59 \%)\end{array}$ & $\begin{array}{l}73,832 \\
(12.85 \%) \\
\end{array}$ & $\begin{array}{l}31,993 \\
(5.57 \%)\end{array}$ \\
\hline $\begin{array}{l}\text { Tweets with user-reported country location in Indonesia (\% } \\
\text { of all tweets with user-reported country location in } \\
\text { Indonesia) }\end{array}$ & $\begin{array}{l}291,641 \\
(72.69 \%)\end{array}$ & $\begin{array}{l}32,167 \\
(8.02 \%)\end{array}$ & $\begin{array}{l}16,008 \\
(3.99 \%)\end{array}$ \\
\hline Geo-tagged tweets (\% of all geo-tagged tweets) & $\begin{array}{l}81,205 \\
(83.45 \%)\end{array}$ & $\begin{array}{l}11,860 \\
(12.19 \%)\end{array}$ & $\begin{array}{l}1,136 \\
(1.17 \%)\end{array}$ \\
\hline $\begin{array}{l}\text { Geo-tagged with coordinates in Indonesia ( } \% \text { of all geo- } \\
\text { tagged tweets with coordinates in Indonesia) }\end{array}$ & $\begin{array}{l}76,787 \\
(84.60 \%)\end{array}$ & $\begin{array}{l}10,189 \\
(11.23 \%)\end{array}$ & $\begin{array}{l}1,049 \\
(1.16 \%)\end{array}$ \\
\hline
\end{tabular}

Disaster management implications: First, although Indonesian is the dominant language, and dominant language of Indonesian tweets, many Indonesian Tweeters exclusively use English and Tagalog. Thus, authoritative early warning tweets sent via Twitter should be in at least the main three languages to ensure coverage. Second, those who list Indonesia as the location but tweet in English may be more affluent, and potentially more able to self-manage in the event of a disaster. Third, there is a small but consistent multi-lingual population, which can possibly be mobilized to spread early warnings. Fourth, due to the high fraction of those in Indonesia tweeting in Indonesian, Twitter will provide better coverage of this population than linguistic minorities.

\subsection{Spatio-temporal Patterns}

Knowing when the population normally tweets (temporal patterns) and from where (spatial patterns) is useful in determining the severity of impact after a disaster event; i.e., different temporal pattern or a formerly high tweeting regions becoming silent, are signals of impact.

\subsection{1 - Dynamics}

Using only tweets geo-tagged to Indonesia, we find that on average, most tweeting is done between $6 \mathrm{pm}$ and $10 \mathrm{pm}$ and on Saturday and Sunday. Interestingly, according to a 2011study, Thursday was the busiest Indonesian tweeting day. ${ }^{16}$ This may reflect shifts in access to the Internet (i.e., moving from warnet and universities to cell phones) or in usage (i.e., moving from news to coordination and gossip). There may be significant variation; e.g., Padang varies slightly from Indonesia as a whole, the single greatest number of tweets was one day at midnight, and on a Wednesday. Hence, for disaster planning, it is necessary to have a good baseline of the likelihood of tweets from locations of interest for each hour of the day for each day of the week.

While we cannot be certain that all collected tweets are from Indonesia, we do see the same pattern overall and in just those geo-tagged within Indonesia (Figure 2, a typical week from CS3). The weekend spike is less pronounced for users than tweets, indicating that variations are a function of specific users being more active rather than more users. Thus, a data collection scheme such as CS5 that focuses on geo-tagged tweets should be representative of the population's general dynamics.

\footnotetext{
${ }^{16}$ http://www.thomascrampton.com/Twitter/indonesia-Twitter-stats/ last accessed - Feb. 2015.
} 

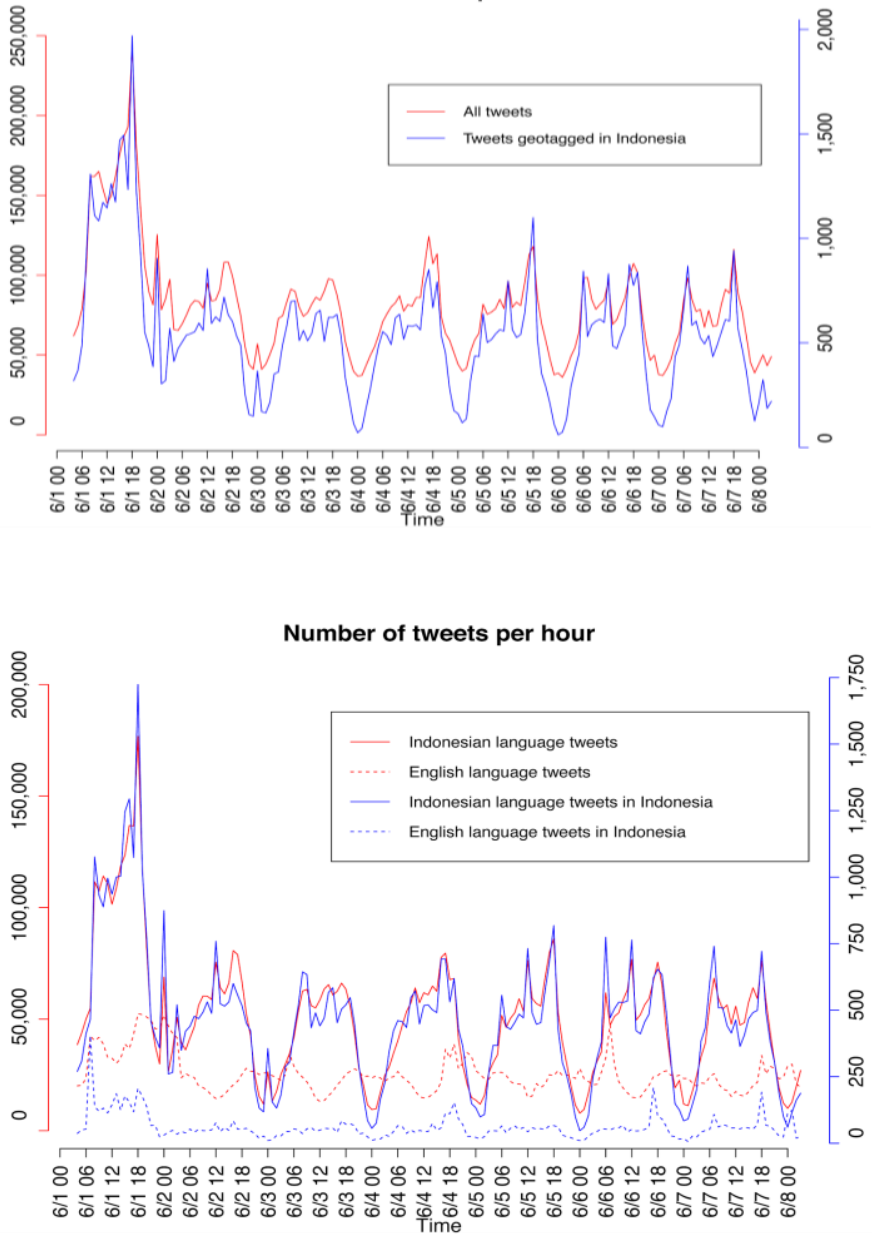

Figure 2. Temporal signature of Twitter for June 1-June7 2014 showing tweets per hour for all tweets and geotagged tweets.

When looking at the Tweets in CS3 by hour for the different language patterns (Figure 3), we find that the English language tweets do not follow the same pattern as the Indonesian language tweets. This suggests that some of these tweets are coming from users with different temporal patterns of activity, most likely because they are in a different time zone (the geo-tagged English tweets with coordinates in Indonesia have a temporal signature that is similar to that of the Indonesian language tweets).

\section{Figure 3. Number of tweets per hour for June 1-June7 2014 showing language differences and similarities.}

There are several implications of this temporal analysis for disaster management. First, Twitter will be less valuable for reaching the population with an early warning on weekdays and between $11 \mathrm{pm}$ and $6 \mathrm{am}$. Second, the rhythm of Twitter usage appears to be related to the overall Indonesian culture and are not linguistically based. Hence, messages do not need to be staged by linguistic group. Third, even though there is a temporal pattern, there appears to always being someone on-line. Efforts to ensure these individuals attend to messages from the authoritative sources and then communicates to the population via non-Twitter means may be an effective warning strategy. Fourth, the distinctiveness of the English tweets suggests that they many of them may not be from Indonesia. Thus knowledge systems for disaster management might want to use the Twitter temporal pattern as a way of ruling out tweets that are not relevant.

\subsection{2 - Geographic distribution}

In CS3 there were tweets from users giving their location as in one of 69 different countries, the most common are shown in Table 4. Similar to language, the greater presence of nearby countries may be topical similarity or from overlapping bounding-boxes. For geo-tagged tweets, we can plot their coordinates over a map of Indonesia or as a heat map showing densities using our Twitter disaster tool (Landwehr et al, this issue). With an Indonesia wide collection strategy (CS1, CS3) Jakarta, the "2011 Twitter capital of the world", will show the most tweets. 


\begin{tabular}{|l|l|l|}
\hline \multicolumn{2}{|c|}{ Table 4. User-reported country location } \\
\hline Country & Tweets & Users* \\
\hline Indonesia & 401,185 & 51,264 \\
\hline Malaysia & 154,035 & 9,001 \\
\hline Philippines & 7,420 & 303 \\
\hline Singapore & 5,545 & 442 \\
\hline Thailand & 3,144 & 148 \\
\hline United States & 1,218 & 826 \\
\hline Australia & 571 & 50 \\
\hline Great Britain & 427 & 273 \\
\hline France & 135 & 96 \\
\hline Total & $574,484(4.20 \%$ of all tweets $)$ & $62,698(1.89 \%$ of all users)* \\
\hline
\end{tabular}

* There were 230 users with tweets with two different countries (i.e., they changed their country designation during the collection period). The 62,698 number is the correct total and does not include multiple counts of the same item.

For geo-tagged tweets, we can plot their coordinates over a map of Indonesia or as a heat map showing densities using our Twitter disaster tool (Landwehr et al, this issue. With an Indonesia wide collection strategy (CS1, CS3) Jakarta, the "2011 Twitter capital of the world", will show the most tweets. Thus for a regional disaster, e.g., one in Padang, a smaller geo-strategy should be used. Even with a narrow strategy, e.g., CS2, CS4, or CS5, the tweets will not be uniformly distributed within cities. For example, in Figure 4, which contains just the geo-tagged tweets for Padang, we see higher levels of tweeting along the coastal areas and less internally. In TWRsms (Landwehr, this issue) this data is shown as a heatmap. If we examine this across multiple days, we find that the majority of the tweets are coming from three areas, which are the locations of universities. We also find strong spatial variance in where tweets are originating from by time of day and day of week.

There are two implications for disaster management. First, although collections using a bounding-box and $1 \%$ feed can provide better regional coverage than the random decahose; they miss most of the user population, and hence may miss critical information about who needs what help. Improved procedures for inferring location based on the user ties (Compton et al., 2014) and the time of day/time zone (Mahmud et al., 2014) are needed. Second, the Twitter population while more likely to be in cities, may not be in the most populated areas of the city. The most detailed spatio-temporal patterns require focused local collection like CS5. This data can support evacuation route planning by providing insight into where people are when. However, given the small fraction of geo-tagged tweets it is likely to be insufficient for identifying those who need to be evacuated. Whether the temporal trails from geo-taggers provide guidance for evacuation is a subject for future study and beyond this paper's scope.

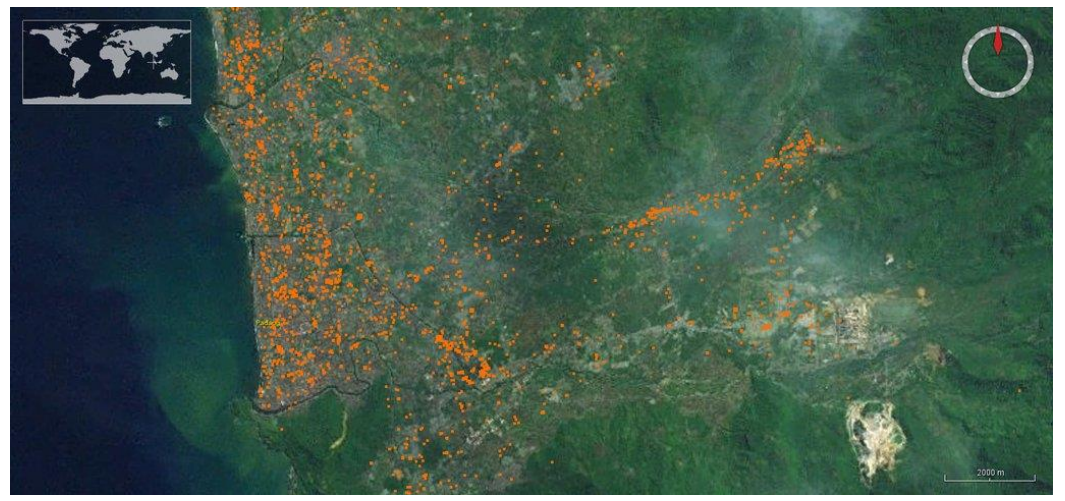

Figure 4. Geographic mapping of geo-tagged tweets for a random Monday in Padang in 2014 using CS5.

\section{3 - Identification of Opinion} Leaders

The simplest way of identifying potential opinion leaders is to see who is mentioned the most, shown in Table 5 based on a week of CS3. Represented there is a bakery in 
Makassar (Chocolicious), ${ }^{17}$ the Indonesian news site Detik, ${ }^{18}$ a media figure (Raditya Dika), and a soap opera actor (Aliando Syarief). ${ }^{19}$ The greater number of news and political commentators most mentioned in geotagged tweets versus the teen celebrities most mentioned in tweets with Indonesia as the user-reported country suggests age differences in the two groups. The Geo-tagged network is dominated by highly central news and political commentary users. In contrast, those who report Indonesia as a country frequently mention stars and various teens and kids, who are prolific users. It may be that the difference between the geo-tagged users and those who report Indonesia as a country is age, with the former being dominated by older users and the latter dominated by very young users, i.e., junior high and high school students. We see a similar difference in the hashtags used with geo-tagged network focusing on hashtags referring to political or economic issues or locations and the Indonesia as country network using hashtags that are more transient and often referring to celebrity events such as birthdays or music releases.

\begin{tabular}{|c|c|c|c|c|c|c|c|c|}
\hline & $\begin{array}{l}\text { Geo-tagged } \\
\text { Indonesian } \\
\text { coordinates }\end{array}$ & & All & & $\begin{array}{l}\text { Indonesian } \\
\text { language } \\
\text { tweets }\end{array}$ & & $\begin{array}{l}\text { User-reported } \\
\text { country location } \\
\text { of Indonesia }\end{array}$ & \\
\hline $\begin{array}{l}\text { Ra } \\
\text { nk }\end{array}$ & Handle & $\#$ & Handle & $\#$ & Handle & $\#$ & Handle & \# \\
\hline 1 & $\begin{array}{l}\text { pilaradio886fm } \\
\text { - news/music }\end{array}$ & 869 & $\begin{array}{l}\text { Chocoliciousm } \\
\text { ks - bakery }\end{array}$ & 89,129 & $\begin{array}{l}\text { Chocoliciousm } \\
\text { ks - bakery }\end{array}$ & 89,127 & $\begin{array}{l}\text { Alysyarief - actor } \\
\text { Aliando Syarief }\end{array}$ & 843 \\
\hline 2 & $\begin{array}{l}\text { Akuekaaj - } \\
\text { Selamatkan } \\
\text { Islam }\end{array}$ & 819 & $\begin{array}{l}\text { Detikcom - } \\
\text { news }\end{array}$ & 75,352 & $\begin{array}{l}\text { Detikcom - } \\
\text { news }\end{array}$ & 72,988 & $\begin{array}{l}\text { aliando26 - actor } \\
\text { Aliando Syarief }\end{array}$ & 516 \\
\hline 3 & $\begin{array}{l}\text { NasDem - } \\
\text { political party }\end{array}$ & 278 & $\begin{array}{l}\text { Erlanhandsom } \\
\text { nia - Erlan } \\
\text { Pratama, } \\
\text { Bogor } \\
\end{array}$ & 30,326 & $\begin{array}{l}\text { Erlanhandsom } \\
\text { nia - Erlan } \\
\text { Pratama, } \\
\text { Bogor }\end{array}$ & 30,325 & $\begin{array}{l}\text { PrillyBie - Prilly } \\
\text { Latuconsina teen } \\
\text { idol }\end{array}$ & 507 \\
\hline 4 & $\begin{array}{l}\text { Moharifwidarto } \\
\text { - commentator }\end{array}$ & & $\begin{array}{l}\text { Pendingmoveo } \\
\mathrm{n}\end{array}$ & 30,309 & $\begin{array}{l}\text { Pendingmoveo } \\
\mathrm{n}\end{array}$ & 30,308 & $\begin{array}{l}\text { Iqbaale - child } \\
\text { idol }\end{array}$ & 489 \\
\hline 5 & \begin{tabular}{|l} 
COVtranstv - \\
Celebrity On \\
Vaction Org
\end{tabular} & 220 & \begin{tabular}{|l} 
Radityadika - \\
Indonesian \\
writer
\end{tabular} & 25,149 & $\begin{array}{l}\text { Radityadika - } \\
\text { Indonesian } \\
\text { writer }\end{array}$ & 24,474 & $\begin{array}{l}\text { AlvaroMaldini1- } \\
\text { child idol }\end{array}$ & 293 \\
\hline
\end{tabular}

Hashtags by tweets (Table 6) and hashtags by users (not shown) reveal similar patterns. The gaming and mobile device/tablet theme suggests a promotional campaign, spam, or entertainment. An exploratory investigation of tweets shows a practice of users tweeting out \#np followed by a song name, suggesting that it is being used as short for "now playing." 20 \#Happy8thAnniversaryELF relates to a Korean pop group.21 \#WeAreARTRILOVERS is something Indonesian but it is unclear what. \#GolkarforPrabowoHatta is a political hashtag: Golkar is a politician and Prabowo-Hatta a political party.

\footnotetext{
${ }^{17}$ http://www.chocoliciousmks.com/ last accessed - Feb. 2015.

18 http://www.detik.com last accessed - Feb. 2015.

${ }^{19}$ http://id.wikipedia.org/wiki/Aliando Syarief last accessed - Feb. 2015.

${ }^{20}$ http://tagdef.com/np last accessed - Feb. 2015.

${ }^{21}$ http://www.allkpop.com/article/2014/06/super-junior-celebrate-the-8th-anniversary-of-official-fanclub-elf last accessed - Feb. 2015.
} 


\begin{tabular}{|c|c|c|c|c|c|c|c|c|}
\hline \multicolumn{9}{|c|}{ Table 6. Most used hashtags (by tweets) } \\
\hline & $\begin{array}{l}\text { Geo-tagged } \\
\text { Indonesian } \\
\text { coordinates }\end{array}$ & & All & & $\begin{array}{l}\text { Indonesian } \\
\text { language } \\
\text { tweets }\end{array}$ & & $\begin{array}{l}\text { User-reported } \\
\text { country location } \\
\text { of Indonesia }\end{array}$ & \\
\hline $\begin{array}{l}\text { Ra } \\
\text { nk }\end{array}$ & Hashtag & \# & Hashtag & $\#$ & Hashtag & \# & Hashtag & \# \\
\hline 1 & NP & 312 & gameinsight & 735,354 & $\begin{array}{l}\text { WeAreARTR } \\
\text { ILOVERS }\end{array}$ & 21,254 & NP & 1,297 \\
\hline 2 & jakarta & 161 & androidgames & 419,389 & News & 16,517 & $\begin{array}{l}\text { Happy8thAnnivers } \\
\text { aryELF }\end{array}$ & 557 \\
\hline 3 & Indonesia & 87 & android & 416,438 & $\begin{array}{l}\text { GolkarforPra } \\
\text { bowoHatta }\end{array}$ & 16,433 & $\mathrm{~Np}$ & 204 \\
\hline 4 & $\begin{array}{l}\text { IndonesiaBang } \\
\text { kit }\end{array}$ & 83 & ipadgames & 235,081 & $\begin{array}{l}\text { ARBdukungP } \\
\text { rabowoHatta }\end{array}$ & 10,810 & $\mathrm{OK}$ & 173 \\
\hline 5 & LMen & 65 & ipad & 233,134 & Tuit & 10,530 & $\begin{array}{l}\text { WeWantBDLBac } \\
\mathrm{k}\end{array}$ & 171 \\
\hline
\end{tabular}

In general, the key actors and most mentioned hashtags will vary by language and region regardless of data collection strategy. From a disaster management perspective this suggests that data should be analyzed via the specific community. We explored this issue with respect to Padang. Using the April and May 2014 CS5 dsta, we constructed a directed network such that a user was linked to another just in case they mentioned or retweeted that other user. There were 5,391 users in the sample and an associated 128,202 tweets with mentions. Of these users only 1,247 actually mentioned or retweeted another. The resulting "network" is not strongly connected and contains multiple components and a large number of isolates and dyads. This suggests that there is no one user who will be automatically serving as a source of information for the entire population at an informal level (keep in mind that at a formal level many users follow the official $\mathrm{BMKG}$ site). It also suggests that there are local opinion leaders who have fairly large circles of followers (e.g., high degree centrality in the mentions network). In one sample of data for Padang, the Twitter handles for the top five of these users are: Saibisikuku, siskatejaa, naolarissa, vionarethaa, and FannySelvina. These individuals are not the most frequent tweeters, but when they do tweet a large number of others pay attention and rebroadcast their messages. Such individuals could effectively spread early warning messages on Twitter, due to their network position. However, we find that: 1) who is top in terms of the mentions network changes rapidly, 2) the list of top mentioning tweeters are likely to contain bots, and 3) these top actors tend to be teenage girls. For example, of the top five referred to above, all are teenage girls. From a disaster management perspective it may be possible to mobilize these users to support early warning activity; however, since they are teenage girls, they are unlikely to be treated as having an authoritative voice by the local community. For disaster management new network metrics for identifying opinion leaders might be needed. Tracking followers is unlikely to work, as users frequently "buy" followers or use bots to increase their apparent following.

\section{6 - Discussion}

For planning and early warning the goal is to use Twitter data to know where the population is when and to "get the word out." In such a case the lack of representativeness of tweeters in terms of their opinions, and the presence of specialized communities on twitter is not an issue. This work suggests that, Twitter can be used to reach and do a situation assessment of the major population 
centers due to high levels of coverage. Its value for remote locations and rural areas is still to be determined. Within cities, the coverage will not be uniform - temporally, geographically, or sociodemographically. Our research further suggests that the informal leaders of these sub-communities may not be those whom policy makers and first responders are used to working with - e.g., teenage girls. Future work should examine whether the opinion leaders found automatically by TWRsms can be leveraged as part of the early warning system.

Baseline data is critical in creating a socio-technical solution. This work shows that a naïve approach to tweet selection cannot be used. Rather, the tweets need to be carefully collected, and then assessed for relevant differences given the linguistic, spatial and temporal subsets. In particular, such Twitter baseline data for planning should focus on tweets from the region of interest, but account for the biases inherent in focusing on geo-tagged data. Care must also be taken in inferring location given language. Future work is needed in this area.

As previously noted, social media usages is strongly integrated into daily life in Indonesia. This is reflected in the fact that, as we found, many of the top hashtags are referring to political and entertainments issues, even though we were attempting to select those tweets that were more related to disaster issues. From a disaster management perspective the good news is that there is a community attending to social media and so training is social media usage is not needed; but the bad news is that there is high volume of non-disaster information that may obfuscate disaster issues and distract users. Future work should explore this issue and determine the extent to which those Indonesians who are tweeting about and following entertainment celebrities are also following the disaster warning agencies such as BMKG.

Twitter data generally is filled with commercial activity and spam. We find little such data (exceptions here are tweets by the suspended accounts and those regarding chocolicious). This may be due to Indonesian Twitter users not focusing on generating or sending commercial tweets, and instead turning to Twitter as a source of celebrity and entertainment news similar to the young adult American Twitter community (Hargittai \& Litt, 2011). Alternatively, this may be a bias introduced by the data collection strategy. Future work should re-examine this issue, and assess the impact of bots on planning and early warning activities.

\section{7 - Conclusions}

An examination of normal Twitter usage in Padang Indonesia demonstrates the viability of using this data as part of the disaster management process for planning and early warning. This baseline assessment is critical for developing the overall knowledge management system. This baseline can be used to establish guidelines on how to collect and use data for planning and early warning, and to set expectations for what Twitter data can and cannot be used for. While we do not claim that this paper provides an exhaustive catalogue of such use, it does demonstrate where the holes are in population coverage, and the limits in using this data as the sole technology for reaching the entire population with information, for determining who is where when, and for identifying those who can be mobilized to support the response effort. We find that despite geoinformation; the level of geo-information is such that it does not provide accurate information on the exact location of each population member. The lack of gender and age information means that Twitter cannot be used to estimate the location of certain at-risk groups.

That being said, this baseline does provide key guidance which influence the socio-technical system described in this issue. Critical findings and their implications are as follows: We find wide spread usage, high prevalence of geo-information, accurate language markers, and active use of and support for Twitter among local officials and official disaster response groups. This suggests that disaster management tools that employ Twitter should be relatively effective in Padang 
Indonesia. Further, the fact that many of the dominant Twitter users are also on other social media platforms, such as Facebook and Instagram, and Twitter is often used in social community settings, suggests that warnings sent via Twitter will cross into other communication spheres. We examined multiple data collection strategies and found that the strategy impacted the data's usefulness for planning and early warning. For Twitter, collection for the geo-spatial region and then postprocessing for disaster related issues is likely to yield more useful data. This strategy generates sufficient coverage that the data can be used for planning as it supports estimating coverage, assessing the spatio-temporal patterns, and identification of opinion leaders. We find that although a large fraction of Indonesians use Twitter, there is high variance in volume of tweets by day of week and hour of day, region of the city, and geo-linguistic groups. This suggests both that normal Twitter usage can be used to inform estimates of where the population is when in systems such as TWRsms (Landwehr et al, this issue) to support planning and that the relative effectiveness of Twitter based warning will vary by time of day, location, and day of week suggesting the need for a multi-media alert system.

We find evidence of multiple languages. In these data, the number of tweets with a userdefined country location are more numerous than even the number of geo-tagged tweets reported elsewhere (Morstatter et al., 2013). This, suggests that in Indonesia, spatial oriented disaster response tools using Twitter may be more effective than in other countries. A large fraction of users who tweet in Indonesian and a non-English language or languages, most often Tagalog. The two languages are only distantly related, so this is likely not a case of linguistic confusion or crossover. This may be a sign of the mobility between Pacific Rim countries. In particular, this may be due to Indonesian (or Malay) expats in the Philippines; or, Filippino expats in Indonesia. From a disaster management perspective this has several implications. First, there are natural conduits in Twitter for information to flow informally between the countries which will be valuable for storms that hit multiple countries. Second, disaster management tools in this region that rely on Twitter, must consider at least 3 languages - Indonesian, Tagalog, and English. Third, reaching groups that might not speak the official language, might be easier than in other countries due to their presence on Twitter. This finding, in conjunction with the high number of components in the mentions network suggest that a Twitter alert strategy should send out messages in all these dominant languages as messages in one language might not be retweeted in another. In addition, the high level of geo-tagging in conjunction with language accuracy suggests that disaster planners should use normal Twitter activities to estimate which regions of the city when are most populated with people with what linguistic needs.

Finally, we find, weakly connected multi-component mentions networks, diverse communities of usage, and large components in which teenage girls are often the local opinion leaders; but, there is high volatility in who is the opinion leader, and these opinion leaders change by topic. This suggests that despite widespread official usage, official authorities like BMKG are not acting as local opinion leaders. Further, although opinion leaders can be automatically identified, they might not be viewed as authoritative. This suggests that a disaster management system that involves Twitter, will need a very comprehensive engagement strategy. For example, local leaders should be engaged as part of an early warning system and response system. This might lead to unexpected new target groups - such as training teenage girls to be information spreaders for the disaster service organizations. Similarly, the government might set up a network with entertainment celebrities so that they tweet critical disaster news. The mobilization of these individuals, however, is likely to increase community resilience by providing a mobile force 
capable of rapidly diffusing information to the broader community and collecting information on problems and re-broadcasting these to authoritative sources.

\section{Acknowledgement}

The author's would like to thank Brendan O'Connor for support in the Twitter analysis and collection. This work was supported in part by the National Science Foundation (NSF) 00361150115291 with support for Twitter analysis of Indonesia and the Office of Naval Research (ONR) N00014140737 with support for

The views and conclusions contained in this document are those of the authors and should not be interpreted as representing the official policies, either expressed or implied, of the NSF, the ONR or the U.S. Government.

\section{References}

Acar, A., \& Muraki, Y. (2011). Twitter for crisis communication: lessons learned from Japan's tsunami disaster. International Journal of Web Based Communities, 7(3): 392-402.

Ai, , F., Comfort L.K., Dong Y. and T. Znati (forthcoming, this issue) A dynamic decision support system based on geographical information and mobile social networks: A model for tsunami risk mitigation in Padang, Indonesia

Anggunia, S. D., \& Kumaralalita, L. (2014, March 13). How Indonesians Use ICT and Social Media for Disaster Management. discover.isif.asia. http://discover.isif.asia/2014/03/howindonesians-use-ict-and-social-media-for-disaster-management/

Asur, S., \& Huberman, B. A. (2010). Predicting the future with social media. arXiv:1003.5699

Barendregt, B., \& Pertierra, R.l (2008). Supernatural mobile communication in the Philippines and Indonesia. In J. E. Katz (ed.), Handbook of mobile communication studies (pp. 377-388). Cambridge, Massachusetts: The MIT Press.

Basuki, T. (1998). Indonesia: The Web as a weapon. Developmental Dialogue 2: The Southeast Asian media in a time of crisis (pp. 96-103).

Birowo, M. A. (2011). Community radio and natural disasters (Indonesia). In J. D. H. Downing (Ed.), Encyclopedia of Social Movement Media (pp. 130-132). SAGE Publications, Inc.

Brenner, S. (1999). On the public intimacy of the new order: images of women in the popular Indonesian print media. Indonesia, 13-37.

Carley, K. M. (2014, forthcoming). Crisis mapping: Big data from a dynamic network analytic perspective. J. of Organization Design.

Carley, K.M., M. Malik, M. Kowalchuk, J. Pfeffer and P. Landwehr, 2015, "Twitter Usage in Indonesia," Carnegie-Mellon University, School for Computer Science, Institute for Software Research, Pittsburgh, Pennsylvania, Technical CMU-ISR-15-109, 2015.

Carver, L. \& Turoff, M., 2007. Human-computer interaction: the human and computer as a team in emergency management information systems. Commun. ACM 50, 3 (March 2007): 33-38.

Castillo, C., Mendoza, M., \& Poblete, B. (2011, March). Information credibility on Twitter. In Proc. of the 20th international Conf. on World wide web (pp. 675-684). ACM.

Center for Excellence in Disaster Management \& Humanitarian Assistance. (2011, May). Country Disaster Response Handbook: Indonesia.

Chatfield, A. T., \& Brajawidagda, U. (2013, January). Twitter Early Tsunami Warning System: A Case Study in Indonesia's Natural Disaster Management. In System sciences (HICSS), 2013 46th Hawaii international Conf. on (pp. 2050-2060). IEEE. 
Chatfield, A. T., Reddick, C. G., Inan, D. I., \& Brajawidagda, U. (2014, June). E-government, social media, and risk perception communication at the edge of disaster: findings from the Mt. Sinabung eruption in Indonesia. In Proc. of the 15th Annual International Conf. on Digital Government Research (pp. 153-162). ACM.

Chatfield, A. T., Scholl, H. J. J., \& Brajawidagda, U. (2013). Tsunami early warnings via Twitter in government: Net-savvy citizens' co-production of time-critical public information services. Government Information Quarterly, 30(4): 377-386.

Cohen, R., \& Ruths, D. (2013). Classifying political orientation on Twitter: It's not easy! In Proc of the Seventh International AAAI Conf. on Weblogs and Social Media (pp. 91-99). http://www.aaai.org/ocs/index.php/ICWSM/ICWSM13/paper/view/6128

Compton, R., Jurgens, D., \& Allen, D. (2014). Geo-tagging One Hundred Million Twitter Accounts with Total Variation Minimization. arXiv:1404.7152

Donath, J. (2007). Signals in social supernets. J. of Comp.-Mediated Comm. 13(1): 231-251.

Earle, P., Bowden, D., \& Guy, M., 2011. Twitter earthquake detection: Earthquake monitoring in a social world, Annals of Geophysics, 54(6): 708-715.

Eickelman, D. F., \& Anderson, J. W. (Eds.). (2003). New media in the Muslim world: The emerging public sphere. Indiana University Press.

Eisenstein, J., O'Connor, B., Smith, N. A., \& Xing, E. P. (2014). Diffusion of lexical change in social media. -- http://arxiv.org/abs/1210.5268

Gaffney, D., \& Puschmann, C. (2013). Data collection on Twitter. In K. Weller, et. al. (Eds.), Twitter and Society (pp. 55-68). New York: Peter Lang.

Gayo-Avello, D. (2012). "I wanted to predict elections with Twitter and all I got was this lousy paper": A balanced survey on election prediction using Twitter data. arXiv:1204.6441

Guha-Sapir, D., \& Lechat, M. F. (1986). Information systems and needs assessment in natural disasters: an approach for better disaster relief management. Disasters, 10(3): 232-237.

Hargittai, E., \& Litt, E. (2011). The tweet smell of celebrity success: Explaining variation in Twitter adoption among a diverse group of young adults. New Media \& Society, 13(5): 824-842.

Hecht, B., \& Stephens, M. (2014). A tale of cities: Urban biases in volunteered geographic information. In Proc. of the Eighth International AAAI Conf on Weblogs \& Social Media (pp. 197-205). https://www.aaai.org/ocs/index.php/ICWSM/ICWSM14/paper/view/8114

Hill, D. T., \& Sen, K. (2000). The Internet in Indonesia's new democracy. Democratization, 7(1): 119-136.

Honeycutt, C., \& Herring, S. C. (2009). Beyond microblogging: Conversation and collaboration via Twitter. In Proc. of the 47th Hawaii International Conf. on System Sciences (pp. 1-10). Los Alamitos, CA, USA: IEEE Computer Society.

Hossmann, T., Legendre, F., Carta, P., Gunningberg, P., \& Rohner, C. (2011, Sept.). Twitter in disaster mode: Opportunistic communication and distribution of sensor data in emergencies. In Proc. of the 3rd Extreme Conf. on Comm: The Amazon Expedition (p. 1). ACM.

Hughes, A. L., \& Palen, L. (2009). Twitter adoption and use in mass convergence and emergency events. International Journal of Emergency Management, 6(3): 248-260.

Ishino, A., Odawara, S., Nanba, H., \& Takezawa, T. (2012, October). Extracting transportation information and traffic problems from tweets during a disaster. In IMMM 2012, The Second International Conf. on Advances in Information Mining and Management (pp. 91-96).

Kireyev, K., Palen, L., \& Anderson, K. (2009, December). Applications of topics models to analysis of disaster-related Twitter data. In NIPS Workshop on Applications for Topic Models: Text and Beyond (Vol. 1). 
Kumar, S. \& Morstatter, F. (2011). “TweetTracker,” [Online]. http://tweettracker.fulton.asu.edu.

Kumar, S., Barbier, G., Abbasi, M. A. \& Liu, H. (2011). "TweetTracker: An Analysis Tool for Humanitarian and Disaster Relief," in Proc. of the 2011 International AAAI Conf. on Weblogs and Social Media, Barcelona, Spain, 2011, pp. 661-662.

Kumar, S., Morstatter, F., \& Liu, H. (2015). Twitter data analytics. Springer Briefs in Computer Science. Springer.

Landwehr, P. \& Carley, K. M. (2014, forthcoming). Social Media in Disaster Relief. In W. W. Chu (ed.), Data Mining and Knowledge Discovery for Big Data, 1: 225-257. Berlin, Heidelberg: Springer.

Landwehr, P., Wei, W., Kowalchuck, M., \& Carley, K.M. (forthcoming, this issue). Using Tweets to Support Disaster Planning, Warning and Response.

Lauder, A. (2008, July). The status and function of English in Indonesia: A review of key factors. Makara, Sosial Humaniora, 12(1): 9-20.

Leetaru, K., Wang, S., Cao, G., Padmanabhan, A., \& Shook, E., 2013, Mapping the global Twitter heartbeat: The geography of Twitter. First Monday, [S.1.], 4/2013. ISSN 13960466. http://firstmonday.org/ojs/index.php/fm/article/view/4366/3654, accessed 10/15/2015.

Lim, M. (2003). The Internet, Social Networks, and Reform in Indonesia. In N. Couldry \& J. Curran (Eds.), Contesting media power: Alternative media in a networked world (ch 17: 273-288). Rowman \& Littlefield Publishers, Inc.

Lim, M. (2013). Many clicks but little sticks: Social media activism in Indonesia. Journal of Contemporary Asia, 43(4):636-657.

Mahmud, J., Nichols, J., \& Drews, C. (2014) Home location identification of Twitter users. ACM Transactions on Intelligent Systems and Technology.

Malik, M., Lamba, H., Nakos, C., \& Pfeffer, J. (2015). Population Bias in Geo-tagged Tweets. In Proc. of 2015 ICWSM Workshop on Standards \& Practices in Large-Scale Social Media Res. (pp. 18-27). http://www.aaai.org/ocs/index.php/ICWSM/ICWSM15/paper/view/10662

Marwick, A. E. \& Boyd, D.. (2011). I tweet honestly, I tweet passionately: Twitter users, context collapse, and the imagined audience. New Media \& Society, 13(1): 114-133.

Meier, P. 2012. "How the UN used social media in response to Typhoon Pablo," iRevolution (8 Dec), at http://irevolution.net/2012/12/08/digital-response-typhoon-pablo/, accessed 10/2015.

Miguel, E., Gertler, P. \& Levine, D. I. (2006). Does industrialization build or destroy social networks? Economic Development and Cultural Change, 54(2): 287-317.

Mislove, A., Lehmann, S., Ahn, Y.-Y., Onnela, J.-P. \& Rosenquist, J. N. (2011). Understanding the demographics of Twitter users. In Proc. of the Fifth International AAAI Conf. on Weblogs and Social Media (pp. 554-557).

Morstatter, F., Pfeffer, J., Liu, H. \& Carley, K. M. (2013). Is the sample good enough? Comparing data from Twitter's Streaming API with Twitter's Firehose. Proc. of the Seventh International AAAI Conf. on Weblogs and Social Media (pp. 400-408).

Muralidharan, S., Rasmussen, L., Patterson, D. \& Shin, J. H. (2011). Hope for Haiti: An analysis of Facebook and Twitter usage during the earthquake relief efforts. Public Relations Review, 37(2): 175-177.

O'Connor, B., Krieger, M., \& Ahn, D. (2010, May). TweetMotif: Exploratory Search and Topic Summarization for Twitter. In Proc. of the AAAI Conf. on Weblogs and Social Media.

Palen, L. \& Vieweg, S. (2008) The Emergence of Online Widescale Interaction in Unexpected Events: Assistance, Alliance \& Retreat. CSCW, ACM Press, 117-126. 
Palen, L., Anderson, K., Mark, G., Martin, J., Sicker, D., Palmer, M. \& Grunwald, D. (2010) A Vision for Technology-Mediated Support for Public Participation \& Assistance in Mass Emergencies \& Disasters. ACM 2010 Conf. on Visions of Computer Science.

Palen, L., Vieweg, S., Liu, S. \& Hughes, A.L. (2009) Crisis in a Networked World: Features of Computer-Mediated Communication in the April 16, 2007 Virginia Tech Event. Social Science Computer Review.

Peduzzi, P., Dao, H., Herold, C. \& Mouton, F. (2009). Assessing global exposure and vulnerability towards natural hazards: the Disaster Risk Index. Natural Hazards and Earth System Science, 9(4): 1149-1159.

Philpott, S. (2000). Rethinking Indonesia: Postcolonial theory, authoritarianism and identity.

Poblete, B., Garcia, R., Mendoza, M, \& Jaimes, A. (2011). Do all birds tweet the same? Characterizing Twitter around the world. In Proc. of the 20th ACM international Conf. on Information and knowledge management October 24-28, 2011, Glasgow, Scotland, UK (p. 1025-1030). New York, NY: ACM Press.

Power, R., Robinson, B., Colton, J. \& M. Cameron, 2014, In Hanachi, C., Bénaben, F., \& Charoy, F. (Eds), Information Systems for Crisis Response and Management in Mediterranean Countries: Proc. of the First International Conf., ISCRAM-med 2014, Toulouse, France, October 15-17, 2014, Springer, New York.

Quarantelli, E. L. (1988). Disaster crisis management: A summary of research findings, Journal of Management Studies 25: 373-385.

Quarantelli, E. L. (1997). Problematical aspects of the information/communication revolution for disaster planning and research: ten non-technical issues and questions. Disaster Prevention and Management: An International Journal, 6(2): 94-106.

Ruths, D. \& Pfeffer, J. (2014). Social media for large studies of behavior. Science, 346(6213): $1063-1064$.

Santos, R.M., D. Mosse, T. Znati, and L.K. Comfort, (forthcoming, this issue) Design and Implementation of a Witness Unit for opportunistic routing in Tsunami Alert Scenarios

Setiyono, B., \& McLeod, R. H. (2010). Civil society organisations' contribution to the anticorruption movement in Indonesia. Bulletin of Indonesian Economic Studies, 46(3): 347-370.

Shalizi, C. R. \& Thomas, A. C. (2011). Homophily and contagion are generically confounded in observational social network studies. Sociological Methods \& Research, 40(2): 211-239.

Sutton, J., Palen, L. \& I. Shklovski. (2008) - Backchannels on the Front Lines: Emergent Use of Social Media in the 2007 Southern California Fires. ISCRAM.

Terpstra, T., de Vries, A., Stronkman, R. \& Paradies, G. L. (2012, April). Towards a realtime Twitter analysis during crises for operational crisis management. In ISCRAM'12: Proc. of the 9th International ISCRAM Conf..

The Asia Foundation, (2014). Elections in Indonesia. Available from https://asiafoundation.org/resources/pdfs/IndonesiaElections.pdf, accessed 10/2015.

Thomas, K., Grier, C., Song, D. \& Paxson, V. (2011). Suspended accounts in retrospect: An analysis of Twitter spam. In Proc. of the 2011 ACM SIGCOMM Conf. on Internet measurement (p. 243). New York, NY: ACM Press.

Thomas, K., McCoy, D., Grier, C., Kolcz, A. \& Paxson, V. (2013). Trafficking fraudulent accounts: The role of the underground market in Twitter spam and abuse. In Proc. of the 22nd USENIX Conf. on Security (pp. 195-210). Berkeley, CA, USA: USENIX Association. Retrieved from http://dl.acm.org/citation.cfm?id=2534766.2534784 
Thomas, R. (1995), “Access and inequality”, in Heap, N., Thomas, R., Einon, G., Mason, R. and Mackay, H. (Eds), Information Technology and Society: A Reader, Sage, London, pp. 90-99. Thomson, R., Ito, N., Suda, H., Lin, F., Liu, Y., Hayasaka, R., ... \& Wang, Z. (2012, April). Trusting Tweets: The Fukushima disaster and information source credibility on Twitter. In 9th ISCRAM Conf. (p. 10).

Tinker, T. \&Vaughan, E. (2010), Risk and Crisis Communications: Best Practices for Government Agencies and Non-Profit Organizations, Booz Allen Hamilton, 2010, p. 30, http://www.boozallen.com/media/file/Riskand-Crisis-Communications-Guide.pdf.

Tobias, E. (2011). Using Twitter and other social media platforms to provide situational awareness during an incident. J. of business continuity \& emergency planning, 5(3): 208-223.

Tufekci, Z. (2014). Big questions for social media big data: Representativeness, validity and other methodological pitfalls. In ICWSM '14: Proc. of the 8th International AAAI Conf. on Weblogs and Social Media (pp.505-514).

van Dijck, J. (2013). The culture of connectivity: A critical history of social media (1st ed.). Oxford; New York: Oxford University Press.

van Oosterom, P., Zlatanova, S. \& Fendel , E. (2006). Geo-information for Disaster Management, Springer, New York.

Vieweg, S., Hughes, A. L., Starbird, K. \& Palen, L. (2010, April). Microblogging during two natural hazards events: what Twitter may contribute to situational awareness. In Proc. of the SIGCHI Conf. on Human Factors in Computing Systems (pp. 1079-1088). ACM.

Wei, W., Joseph, K., Liu, H. \& Carley, K.M. (2015). The Fragility of Twitter Social Networks against Suspended Users. In Proc. of the ASONAM Conf. Paris, France.

Weller, K., Bruns, A., Burgess, J., Mahrt, M., \& Puschmann, C. (eds.). (2014). Twitter and society. New York: P. Lang.

Wong, F. M. F., Sen, S., \& Chiang, M. (2012). Why watching movie tweets won't tell the whole story? arXiv:1203.4642.

Yates, D., \& Paquette, S. (2011). Emergency knowledge management and social media technologies: A case study of the 2010 Haitian earthquake. International Journal of Information Management, 31(1): 6-13.

Zhang, D., Zhou, L., \& Nunamaker Jr, J. F. (2002). A knowledge management framework for the support of decision making in humanitarian assistance/disaster relief. Knowledge and Information Systems, 4(3): 370-385. 
